\title{
Climate Finance and Its Role towards the Transition to Low-Carbon, Climate-Resilient Development in Ethiopia
}

\author{
Zelalem Dendir1
}

\begin{abstract}
Achieving and sustaining stability for economic growth remain the greatest and most immediate development challenge for Ethiopia. For natural resource-based economies especially maintaining stability and growth depends fundamentally upon climate change adaptation and mitigation. The close links between climate and Ethiopia's economy are reflected by the strong relationship between GDP growth rate and rainfall variability. A recent study by the World Bank projects that unless steps to build resilience are effective, climate change will reduce Ethiopia's GDP growth by between 0.5 and $2.5 \%$ each year. Along with the challenges posed by climate change, a number of development opportunities are emerging in response to climate change which includes access to international climate finance. The international response to climate change in the form of external development finance plays a key role to support developing countries in their transition to a low-carbon, climate-resilient and sustainable development pathway. Therefore, this study was conducted to assess the flow and the overall contribution of climate finance to sustainable development in Ethiopia. Specifically, focused on outlining how climate finance is currently reconciled in the existing Ethiopian climate change governance and its contribution to sustainable development. In order to achieve these objectives, data were collected from different sources. The Rio Marker methodology applied to review climate financial flow over the 5 year period. The result reveals that, climate change is central to development agendas despite its recent emergence in the mainstream, with various initiatives under way to combat or reduce its impacts in Ethiopia. In addition, the amount of climate finance from the developed countries to Ethiopia shows some fluctuation for the past five years. In general, the overall flow of climate finance mostly targeted climate adaptation actions which spur and enable the transition towards climate-resilient growth and sustainable development.
\end{abstract}

Keywords: Climate Finance, Sustainable Development, Adaptation Strategies, Green Economy

${ }^{1}$ PhD Candidate, Addis Ababa University, +251912316251, zelalemdendir@gmail.com 


\section{Introduction}

Achieving and sustaining stability for economic growth and equitable human development remains the greatest and most immediate development (Fisher, 2013). For natural resource-based economies especially maintaining stability and growth depends fundamentally upon climate change adaptation and mitigation (Bizikova, et al., 2007). The close links between climate and Ethiopia's economy are reflected by the strong relationship between Growth Domestic Product (GDP) growth rate and rainfall variability. A recent study (World Bank, 2010) by the World Bank projects that unless steps to build resilience are effective, climate change will reduce Ethiopia's GDP growth by between 0.5 and $2.5 \%$ each year. As a worst case scenario, in 25 years time, Ethiopia will have only half the potential total GDP it could have attained and this will be because of the negative impacts of climate change.

One unjust irony of climate change is that even though developing countries have historically contributed less to emissions and most continue to have a small carbon footprint, as a group they suffer earliest and most from harmful shifts in the environment. The poorest in particular are heavily dependent on agriculture for food and incomes; it is the economic sector most sensitive to climate change (Fisher, 2013). And they have fewer resources, in finance, technology and existing infrastructure, to adapt to what lies ahead. Some studies estimate that for every $1{ }^{0} \mathrm{C}$ rise in average global temperatures, annual average growth in poor countries could drop by 2 to 3 percent, with an associated cost in human development and basic survival (Homer et al., 2009).

The international climate change regime is cognizant of the justice implications of climate change (Schlosberg, 2007). However, the response to these concerns is still evolving and progress is being achieved in a slow and incremental manner. The international response to climate change in the form of external development finance plays a key role to support developing countries in their transition to a low-carbon, climate-resilient and sustainable development pathway (World Economic Forum, 2014). Delivery of such finance occurs through technical assistance to strengthen enabling environments and build capacity in developing countries and through direct support to adaptation and mitigation activities. Financing climate change and development in an integrated manner can maximize climate and development results, targeting both climate and sustainable development goals (Swart, 2003). 
Since Ethiopia's livelihoods and economy are dependent on climate sensitive sectors that have limited capacity to cope with climate-induced impacts, building climate resilience economy is thus a key priority for the country. Climate change is central to development agendas despite its recent emergence in the mainstream, with various initiatives under way to combat or reduce its impacts in Ethiopia. Among this, a transition to a climate resilient green economy is estimated to cost in excess of USD150 billion over the next 20 years (Federal Democratic Republic of Ethiopia, 2011). Within the broader global agenda on climate change, Ethiopia stands to gain from climate finance. The government is preparing financial arrangements that will mobilize, manage and disburse financial resources in support of the country's Climate Resilience Green Economy (CRGE) objectives (FDRE, 2011). In general along with the challenges posed by climate change, a number of development opportunities are emerging in response to climate change which includes access to climate finance, technology transfer and capacity building measures.

\subsection{Objectives of the Study General Objective of the Study}

The general objective of the study is to assess the flow and the overall monetary contribution of climate finance towards the transition to climate-resilient sustainable development in Ethiopia

\section{Specific Objectives of the Study}

$>$ Outlining how climate finance is currently reconciled in the existing Ethiopian climate change governance and its contribution to sustainable development.

$>$ To assess the current status and trends of climate finance flow to climate adaptation and mitigation efforts

\section{Methodology of the Study}

The study deals with the flow and the overall contribution of climate finance to sustainable development in Ethiopia. The methodology of the study combines both qualitative and quantitative approach. A qualitative analysis applied for the policy context and institutional arrangements and a quantitative review conducted for climate finance flow and its contribution to sustainable development. The data sources were, for the quantitative study Organization for Economic Co- 
operation and Development- Development Assistance Committee (OECD-DAC) data source used and for the qualitative study government and other sources were sited.

The Rio Marker methodology applied to review climate financial flow over the 5 year period, 2009-2013 to identify the status, trend, source and objectives of climate finance flow to Ethiopia.

Rio Marker: Since 1998 the DAC Development Assistance Committee has monitored aid targeting the objectives of the Rio Conventions through its Creditor Reporting System (CRS) using the "Rio Markers". Rio Marker methodology indicates donors' policy objectives in relation to each aid activity (OECD, 2011). Activities marked as having a "principal" climate change objective would not have been funded but for that objective; activities marked "significant" have been formulated or adjusted to meet the objective.

Climate change mitigation-related aid is defined as activities that contribute to the objective of stabilization of greenhouse gas (GHG) concentrations in the atmosphere at a level that would prevent dangerous anthropogenic interference with the climate system by promoting efforts to reduce or limit GHG emissions or to enhance GHG sequestration (OECD, 2011).

Climate change adaptation-related aid is defined as activities that aim to reduce the vulnerability of human or natural systems to the impacts of climate change and climate-related risks, by maintaining or increasing adaptive capacity and resilience. This encompasses a range of activities from information and knowledge generation, to capacity development, planning and the implementation of climate change adaptation actions (OECD, 2011).

However, there is no internationally agreed methodology for tracking the exact share of aid activity expenditure that contributes to climate change adaptation or mitigation. This is particularly true for adaptation given its intricate linkages with development. Until such a methodology exists, the Rio Markers will allow an approximate quantification of the amount of aid that targets climate change concerns, but not the exact amount of aid specifically directed to helping developing countries mitigate or adapt to climate change. 


\section{Theoretical and Empirical Review}

\subsection{What is Climate Finance?}

Climate finance refers to financing channeled by national, regional and international entities for climate change mitigation and adaptation projects and programs. They include climate specific support mechanisms and financial aid for mitigation and adaptation activities to spur and enable the transition towards low-carbon, climate-resilient growth and development through capacity building, R\&D and economic development (Barbara Buchner et al, 2011). The term has been used in a narrow sense to refer to transfers of public resources from developed to developing countries, in light of their UN Climate Convention obligations to provide "new and additional financial resources," and in a wider sense to refer to all financial flows relating to climate mitigation and adaptation (Oscar Reyes, 2013).

Climate finance involves flows of funds from developed to developing nations to help poorer countries to cut their emissions and adapt to climate change. The sources and governance of climate finance has been widely debated since the 2009 climate change summit in Copenhagen, where industrialized countries committed to giving $\$ 100$ billion a year in additional climate finance from 2020 onwards. In 2010-11 global climate finance flows reached approximately USD 343-385 billion (Barbara Buchner et al., 2012).

Climate finance has been a central element of the international climate change agreements from the outset. The United Nation Framework on Climate Change's (UNFCCC) Cancun Agreements affirm that 'scaled-up, new and additional, predictable and adequate funding shall be provided to developing country Parties' (Cancun Agreements, 2010). This international climate finance offers several opportunities for countries to drive their own sustainable development agenda.

First, the stipulation for 'new and additional' funding over existing overseas development assistance is an opportunity for countries to exert control and ownership over resource allocation and investment decisions, since these are not governed as international aid.

Second, the emphasis on 'scaled-up' climate finance means international funds are designing innovative instruments that can also leverage resources and investments from other sources. This 
trend is expected to grow, providing a route to scalable national approaches to climate-resilient development.

Third, an emphasis on climate finance helping integrate climate actions into development planning (UNFCC, 2011) is bringing adaptation efforts into national development planning.

\subsection{Adverse Impacts of Climate Change for Developing Countries}

The 'adverse effects of climate change' are defined within the United Nations Framework Convention on Climate Change (Framework Convention) 'as the physical environment or biota resulting from climate change which have significant deleterious effects on the composition, resilience or productivity of natural and managed ecosystems or on the operation of socioeconomic systems or on human health and welfare' (UNFCC, 1992). The adverse impacts of climate change are thought to have more serious ramifications for developing countries given their lack of financial and technological resilience.

The inequality of climate change arises from the fact that the communities most vulnerable to the associated impacts are those least responsible for the current levels of greenhouse gas emissions in the global atmosphere (Adger, 2003). Two-thirds of the increase in atmospheric greenhouse gases over the past 150 years stem from industrialized countries (Bert Metz, 2002). It is therefore the previous emissions of industrialised nations that cause current global warming (Diana, 2009). Developed countries are both the main contributors to greenhouse gas emissions and the main beneficiaries of the profits generated by greenhouse gas emitting industries (Ruchi Anand, 2004). There is thus a tension between the competing interests of reducing global greenhouse gas emissions and promoting economic growth within developing states. It is recognised that the exercise of the right to development in many instances will result in more emission contributions from these states. Climate change can thus be viewed as raising a number of justice issues. Firstly, it is argued that developing nations bear a burden of climate change harm that is disproportionate to their contribution to greenhouse gas emissions and secondly mitigation of climate change through the limitation of industrial activities causing greenhouse gas emissions can be construed as interfering with developing countries' 'rights to development'.

All of the above trends are compounded by the lack of economic and technical resources within 
developing countries that would allow for the implementation of adaptation measures (Bert Metz, 2002). One of the primary challenges for the adaptation regime is to ensure that parties contribute funds to assist vulnerable countries in implementing policies and practice to reduce vulnerability. Article 11 of the Framework Convention establishes a financial mechanism to provide financial resources and technology transfer to assist in the implementation of the convention. There are different bi-lateral and multi-lateral climate finance sources, which funds adaptation activities in vulnerable countries.

\subsection{Existing Climate Change Financing Mechanisms in Africa}

Various sources of funding for climate change exist worldwide and the architecture of such funding mechanisms is complex. Sources include multi-lateral and bi-lateral funds, the private sector and charitable organizations. They can also be grouped by scope (adaptation, mitigation, both, Reducing Emission from Deforestation and Deforestation (REDD) etc.) or by whether they fall under or outside the UNFCCC. Of the Rio Conventions, the UNFCCC has received much attention and, subsequently, funding for its objectives. In 2007, the Development Assistance Committee of the OECD (DAC) allocated approximately USD 4.3 billion in climate change related aid, compared to USD 3.5 billion and USD 1.7 billion in biodiversity and desertification related aid, respectively (OECD-DAC, 2009).

Table 1 Overview of Major Funding Mechanisms in Africa

\begin{tabular}{|c|c|c|c|}
\hline & Multilateral Funds & Managed by & Year \\
\hline \multirow[t]{7}{*}{ Adaptation } & Least Developed Countries Fund & $\begin{array}{l}\text { Global } \\
\text { Environmental } \\
\text { Facility (GEF) }\end{array}$ & 2002 \\
\hline & Special Climate Change Fund & GEF & 2002 \\
\hline & Strategic Priority on Adaptation & GEF & 2004 \\
\hline & Adaptation Fund & GEF & 2009 \\
\hline & $\begin{array}{l}\text { Millennium Development Goal (MDG) } \\
\text { Achievement Fund- Environment and Climate } \\
\text { Change Thematic Window }\end{array}$ & $\begin{array}{l}\text { United Nation } \\
\text { Development } \\
\text { Program (UNDP) }\end{array}$ & 2007 \\
\hline & Climate Investment Funds & \multirow[t]{2}{*}{ World Bank } & 2008 \\
\hline & $\begin{array}{l}\text { - Strategic Climate Fund } \\
\text { a. Pilot Program for Climate Resilience } \\
\text { (PPCR) }\end{array}$ & & $2008-2009$ \\
\hline
\end{tabular}




\begin{tabular}{|c|c|c|c|}
\hline & $\begin{array}{ll}\text { b. Forest Investment Program } \\
\text { c. Scaling-up Renewable Energy } \\
\text { Program for Low Income Countries } \\
\text { (SREP) }\end{array}$ & & \\
\hline \multirow[t]{3}{*}{ Mitigation } & - Clean Technology Fund & & \\
\hline & $\begin{array}{l}\text { Global Energy Efficiency and Renewable } \\
\text { Energy Fund }\end{array}$ & $\begin{array}{l}\text { European } \\
\text { Commission } \\
(\mathrm{EC})\end{array}$ & 2008 \\
\hline & UN-REDD & UNDP & 2008 \\
\hline \multirow{3}{*}{$\begin{array}{l}\text { Adaptation } \\
\& \\
\text { Mitigation }\end{array}$} & GEF Trust Fund & GEF & 2006 \\
\hline & Green Climate Fund & $\begin{array}{l}\text { UNFCCC } \\
\text { Secretariat }\end{array}$ & \\
\hline & Bi-lateral Funds & Managed by & Year \\
\hline \multirow{7}{*}{$\begin{array}{l}\text { Adaptation } \\
\& \\
\text { Mitigation }\end{array}$} & Strategic Climate Fund & World Bank & 2008 \\
\hline & Global Climate Change Alliance & EC & 2008 \\
\hline & International Climate Fund & UK & 2011 \\
\hline & International Climate Initiative & Germany & 2008 \\
\hline & International Forest Carbon Initiative & Australia & 2007 \\
\hline & Fast Start Finance (Private and public source) & Japan & 2008 \\
\hline & International Climate and Forest Initiative & Norway & 2008 \\
\hline
\end{tabular}

\subsection{Sustainable Development Approach}

\subsubsection{Sustainable Development Definition}

In 1987 the Bruntland report defined sustainable development as "development that meets the needs of the present without compromising the ability of future generations to meet their own needs" (World Commission on Environment and Development, 1987). Other definitions have been provided which illustrate various dimensions of sustainable development, reflecting the different views on development of economists, ecologists and sociologists; hence there remains disagreement regarding its theoretical definition and practical implications. Nonetheless there is general agreement that sustainable development requires the effective integration of three key elements: the economic, social and environmental dimensions of development.

Generally speaking any policy pursuing sustainable development needs to: -

Ensure economic development;

Improve rational use of natural resources; 
$>$ Preserve the ecosystem's functions;

$>$ Enhance social well-being.

Furthermore the sustainable development frame work incorporates a focus on the equitable distribution of wealth in the society, therefore aiming towards poverty alleviation. A dimension of equity within and across countries is also embodied into the broad definition.

\subsubsection{Sustainable Development Indicators/Goals}

The most common way of measuring the sustainability of policy interventions or of projects is through the use of sustainability indicators (Atkinson et al., 2007). National governments and international organizations have well-established principles of sustainable development as part of their national laws.

For example, sustainable development criteria is often incorporated into existing environmental laws, incorporated as part of general environmental impact assessment processes or as discrete national policies (IISD, 2006). While standard economic indicators, like GDP and inflation, are widely accepted, progress has to be made in the production and dissemination of social and environmental indicators.

Although the term "sustainable development" is open to many different interpretations, there is some agreement on the defining principles. These include environmental protection, social advancement and economic development. There are also procedural components to sustainable development, such as transparency, community participation and access to justice. Countries that do not have an existing set of development priorities or strategies may use the sustainable development frameworks provided by international agencies, such as the United Nations Commission on Sustainable Development (“UNCSD”), as a working model (Atkinson et al., 2007). Despite the existence of such generic principles of sustainable development that will apply to most countries, each Country needs to take a decision on how it will assess whether a policy meets sustainable development objectives based on the unique conditions and needs of that country. The country could either formulate or adopt sustainable development criteria or it could refer to existing law stating that policies that are in compliance with the existing regulatory framework fulfill (existing) sustainable development criteria or principles. This will enable policy 
developers to determine, very early in the policy formulation stage, whether or not a proposed policy will meet specific Country sustainable development requirements.

Indicators offer a practical way to assess data on social, environmental and economic conditions and when integrated at a sectoral level prove very useful in evaluating the impact of policies at the sectoral level itself are the "resources" indicators, which may be used to characterize the quality of development that is being achieved.

\subsubsection{The Sustainable Development Dimension of Climate Finance}

While there has been much speculation about how much climate finance might help to achieve and how to calculate baselines, less attention has been paid to the question of how much sustainable development the climate finance will contribute to achieving in developing countries (Aaron, 2009). A part of the answer lies in the estimated increased investment flows to developing countries. This will also influence the nature of the activities that will take place in these countries. Another part lies in the actual "amount" of sustainable development resulting from climate finance. Overall, climate finance could contribute to sustainability within the host country: -

1. By providing increased man-made capital such as technology transfer, infrastructure building, improved economic efficiency;

2. By improving environmental capital such as air or water quality;

3. By improving social and human standards of living through the creation of jobs or the transfer of knowledge (Swart, 2003).

\subsection{Climate Change as Ethiopia's Sustainable Development Challenge}

Climate change and weather extremes are already the threats to Ethiopia's economy and social wellbeing.

Agriculture: Agriculture, primarily rain-fed and highly sensitive to fluctuations in rainfall, forms the basis of the economy. For instance, agriculture contributes around 45 per cent to GDP. Approximately 83 per cent of the population depends directly on agriculture for their livelihoods, with many more reliant on agriculture-related industries. With only 0.5 per cent of agricultural 
land with access to irrigation - agriculture is predominantly rain-fed and as such vulnerable to the impacts of climate change and extreme weather events (Evans, 2012).

Droughts can result in sharp reductions in agricultural output and related productive activity and employment, with multiplier effects on the monetary economy. For example, the major drought in 2002-3 resulted in a drop in food production by 26 per cent (Barnett et al. 2009). Floods regularly cause crop and infrastructure damage and widespread suffering and hardship, with, for example, several tens of thousands of people being displaced and over ten thousand hectares of cropland inundated in Afar and Amhara regions in 2010. Moreover, Greater total or more intense rainfall across Ethiopia may increase soil erosion and the incidences of crop damage. Ethiopia is particularly vulnerable to accelerated soil erosion because of existing pressures and degradation on land area. There will also be changes in production system viability; cropland area and cropping patterns; pest and disease frequency and distribution brought about by changes in seasonality; timing and distribution of rainfall; higher evapotranspiration; drought and flood damage (FDRE, 2011).

Transport: Improvement and maintenance of transport links between urban centres, to and from ports of export and import, and in particular to rural areas are a pre-requisite for economic development. However transport links, both paved and unpaved roads, are highly vulnerable to the increases in rainfall and temperature which are projected for Ethiopia, with heavy rainfall washing out roads and high temperatures damaging road surfaces. The National Adaptation Programme of Action (NAPA) identifies the infrastructure sector as particularly vulnerable to climate change impacts (Ministry of Water Resource, 2007). A World Bank study projects that climate change will increase the maintenance costs of the country's road network by between $\$ 10$ million to $\$ 21$ million, depending on the climate model used (World Bank, 2010). These costs will be reduced and transport links maintained if road drainage and bridge designs are adapted to the expected climatic conditions. Maintenance costs of unpaved roads are also high and extending the network of paved roads is likely to be economically beneficial.

Industry: Ethiopia's economic development will require an expansion of industrial activities. Some of the industrial sectors, such as textile and leather, will allow the country to increase its export; others, such as cement and steel, will expand largely for domestic infrastructure 
development. While the growth of industrial sectors has the highest priority, Ethiopia will face a challenge related to GHG emissions caused by these activities. Ensuring the transfer of modern and resource efficient technologies is therefore an important component of growth plans.

Energy: The vast majority of Ethiopia's national energy needs are derived from fuel wood, crop and animal waste and human and animal power. Only 5\% comes from electricity and $95 \%$ of this is generated by hydro-power (Beyene and Koch, 2012). This energy mix greatly increases the country's vulnerability to climate change. For example, reliance on fuel wood and charcoal brings widespread land degradation, exposing bare soil to erosive rainfall and gulley erosion.

Energy generated by hydropower is also vulnerable to fluctuations in rainfall, temperature and evaporation. For example, reduced power production during drought years already takes a significant toll on the economy. In 2002/3 power supply was lost one day a week over four months because of drought (World Bank, 2010). This caused a sustained reduction in GDP generation. Loss of electricity also impacts on basic services especially in schools and hospitals.

Ethiopia plans to significantly increase its hydroelectric power production in order to supply neighbor countries. Whilst these plans offer huge potential to power low carbon growth in Ethiopia and beyond, they need to carefully consider the implications of future climate change so that benefits can be sustained and conflicts with other water users avoided.

Health: The health impacts of climate change will be felt through six mechanisms:

Morbidity and mortality through temperature extremes;

$>$ Increases in vector borne diseases, such as malaria and bilharzia;

$>$ Increases in non-vector borne diseases related to weather conditions, for example diarrhoeal disease and cholera associated with both floods and drought;

$>$ Health problems associated with weather related air quality;

$>$ Injury and mortality through floods and storms;

Impacts of climate related influences on food and water supply, for example, malnutrition.

In a 2004 study (Homer et al., 2009) it was calculated that 36,000 lives were already being lost each year across Eastern Africa (including Ethiopia) because of climate change. The same study 
calculates that the greatest future health risks associated with climate change in 2030 will be flooding, followed by malaria, diarrohoeal disease, malnutrition and cardiovascular diseases.

For example, the 4th report of the Intergovernmental Panel on Climate Change (IPCC) states that by the 2050s malaria will have entered into the highland areas of Ethiopia and that by 2080 conditions will be highly suitable for malaria transmission (IPCC, 2007).

Environmental resources: Water, soil, land, forests and biodiversity are the foundations of Ethiopia's economic development, food security and livelihood sustenance and each of them faces additional pressures through climate shocks and stresses. Climate change compounds a number of challenges facing natural resources management. According to Ethiopia's National Adaptation Programme of Action water resources and other environmental resources will be most negatively impacted by climate change (National Metrology Agency, 2007).

\section{Result and Discussion}

\subsection{Policy Frameworks and Institutional Arrangements to Access International Climate Finance}

The argument for aligning climate finance and development finance is that it results in a more efficient use of financial and human resources than if climate change and development projects are designed and implemented separately. This objective should be pursued-all projects should, to the extent possible, contribute both to development and to climate change mitigation and/or adaptation.

Policy frameworks: Sustainable development objectives are embedded within environment, climate change and national development policy frameworks in Ethiopia.

The National Environmental Policy (NEP) and the Environmental Protection Organs Establishment Proclamation of 2002 (No. 295/2002) provide the overarching policy and legal context for policy responses to climate change. The NEP outlines policy objectives that pertain to climate change, including a focus on climate monitoring, control of greenhouse gases and use of renewable energy. Proclamation No. 295/2002 established the Environmental Protection Agency and gave it the statutory mandate to coordinate the national response to climate change (FDRE 
2002). Proclamation 803/2013 passes this mandate onto the Ministry of Environment and Forests (FDRE, 2011).

The government of Ethiopia also ratified the United Nations Framework Convention on Climate Change (UNFCCC) in 1994 and initiated the process of preparing specific climate change policies in 2007. These range from programme documents like the NAPA (2007), Nationally Appropriate Mitigation Actions (NAMA) (2010) and the Ethiopian Program of Adaption to Climate Change (EPACC) (2010), to the strategy documents like the CRGE Vision and Strategy (2011), and to proclamations like the New Energy Proclamation (2013). Broadly, these policy documents articulate the country's objectives around climate resilience and sustainable economy.

In 2010, the country's priority objective of building a climate resilient green economy was reinforced by the national development planning process when CRGE was integrated into the Growth and Transformation Plan. The Growth and Transformation Plan addresses climate change as a crosscutting issue under the strategic priority of 'environment and climate change' (MoFED, 2010). It outlines 'building a climate resilient green economy' as a strategic priority as a way to counter development losses caused by climate change.

Institutional arrangements: A transition to a climate resilient green economy is estimated to cost in excess of US $\$ 150$ billion over the next 20 years (FDRE, 2011). The government is preparing financial arrangements that will mobilise, manage and disburse financial resources in support of the country's CRGE objectives. The Ministry of Finance and Economic Development is responsible for financial aspects of the CRGE process.

\subsection{Climate Finance Flow, Trend and Composition in Ethiopia}

Total bilateral and multilateral climate-related development finance data recorded in DAC Statistics reached USD 370 million in 2013, of which $62.3 \%$ addresses adaptation only, $18.8 \%$ mitigation only, and $18.9 \%$ consists of activities designed to address both adaptation and mitigation in Ethiopia.

Figure 1 Trend \& composition of climate finance Flow in Ethiopia 


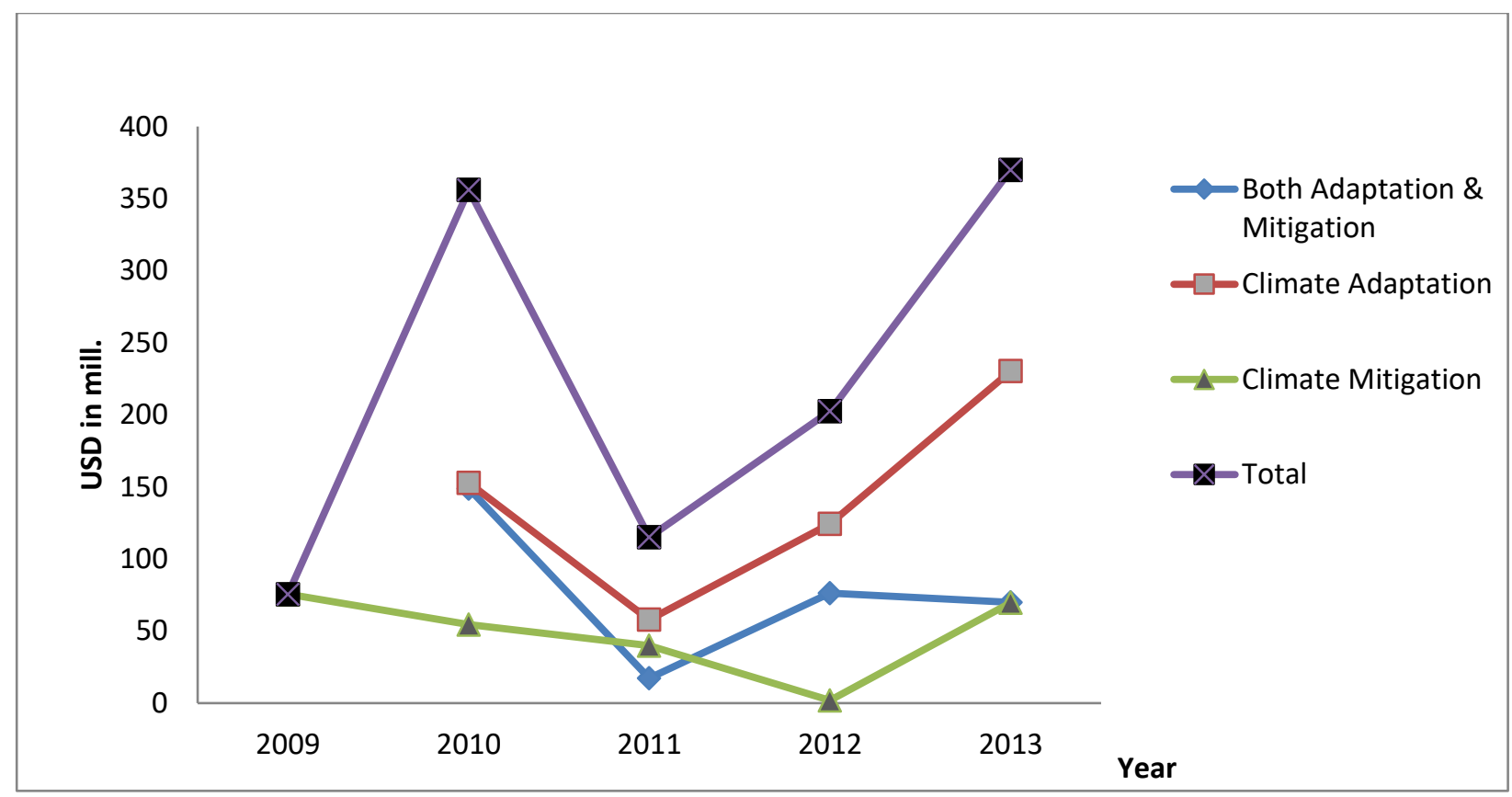

Source: OECD-DAC (2009-2013)

Targeting adaptation and mitigation simultaneously reflects the multiple co-benefits from jointly mainstreaming both objectives into development efforts, provided programmes are well designed. Finance may target more than one policy objective. A key feature of the OECD-DAC Rio marker system is that it records activities that target both mitigation and adaptation objectives simultaneously, allowing multiple objectives to be tracked, while ensuring that this finance is not counted twice.

Of total climate-related aid committed to Ethiopia in 2013, USD 70 million addresses both adaptation and mitigation. This "overlap" reflects the multiple co-benefits and synergies from targeting mitigation and adaptation simultaneously. The overlap is most frequent in the agriculture, forestry, in the water supply and sanitation, and in the general environmental protection sectors.

Total adaptation-related aid commitments to Ethiopia reached USD 230.3 million in 2013, increasing from USD 152.72 million in 2010. It reflects high levels of mainstreaming of adaptation within development co-operation activities, typically being delivered as capacity-building activities in the water supply and sanitation, agriculture, forestry and rural development sectors. 
Total mitigation-related aid commitments to Ethiopia reached USD 69.6 million in 2013. This reflects projects delivered through aids in the energy generation and supply and other sector.

\subsection{Climate Finance Commitments by Countries}

Figure 2 Top 10 sources of climate finance (2009-2013)

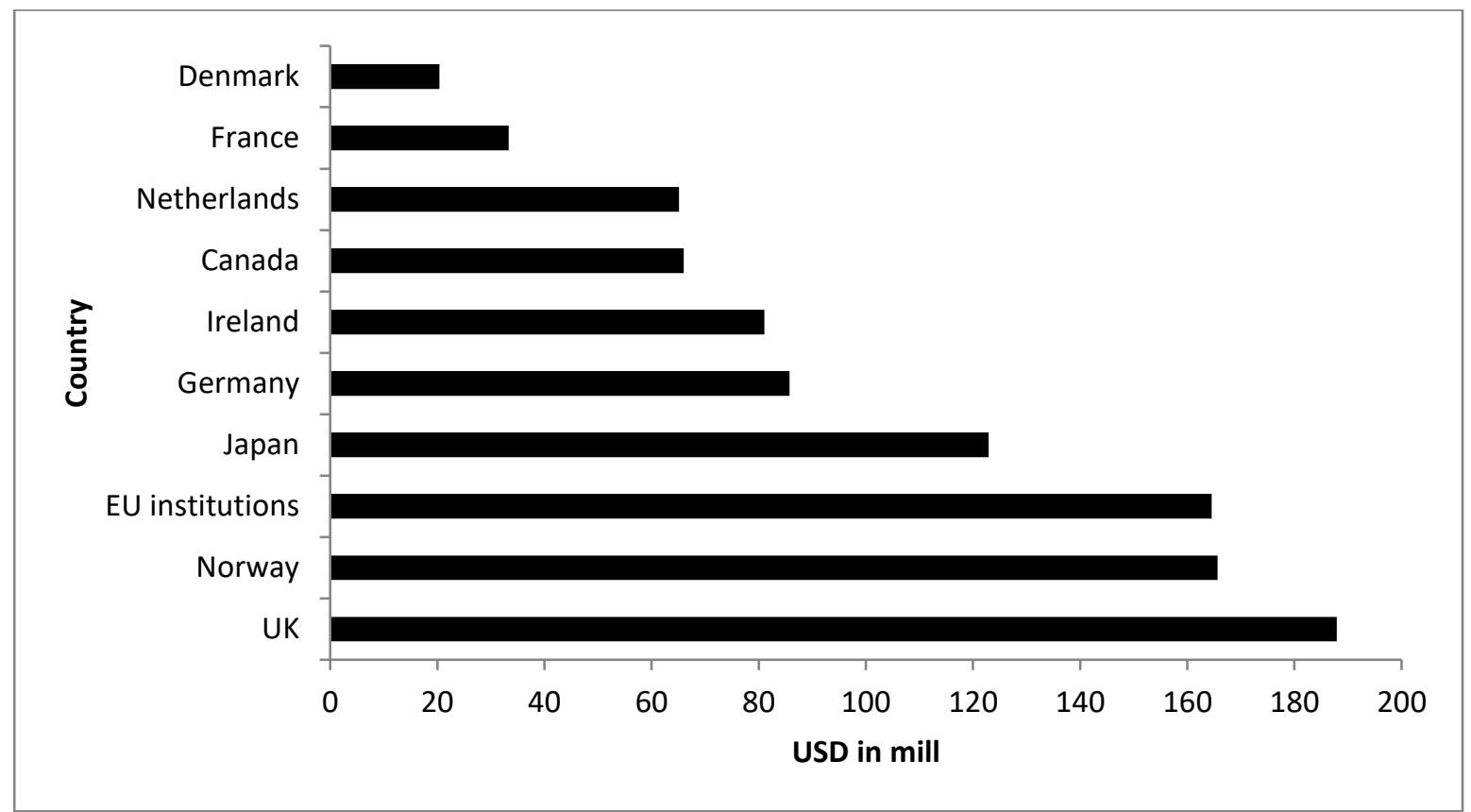

Source: OECD-DAC (2009-2013)

Over $60 \%$ of total climate-related aid to Ethiopia over $2009-13$ is provided by UK, Norway, European Union Institutions, and Japan. Climate-related aid as a proportion of a donor's aid portfolio gives an indication of the priority donors are giving to addressing climate change in Ethiopia. Germany, Ireland, Canada, Netherlands, France and Denmark contribute 32.99\% of aid to Ethiopia to address climate change. 


\subsection{Sectors Targeted By Climate-Related Development Finance}

Figure 3 Targeted Sectors by Climate Finance

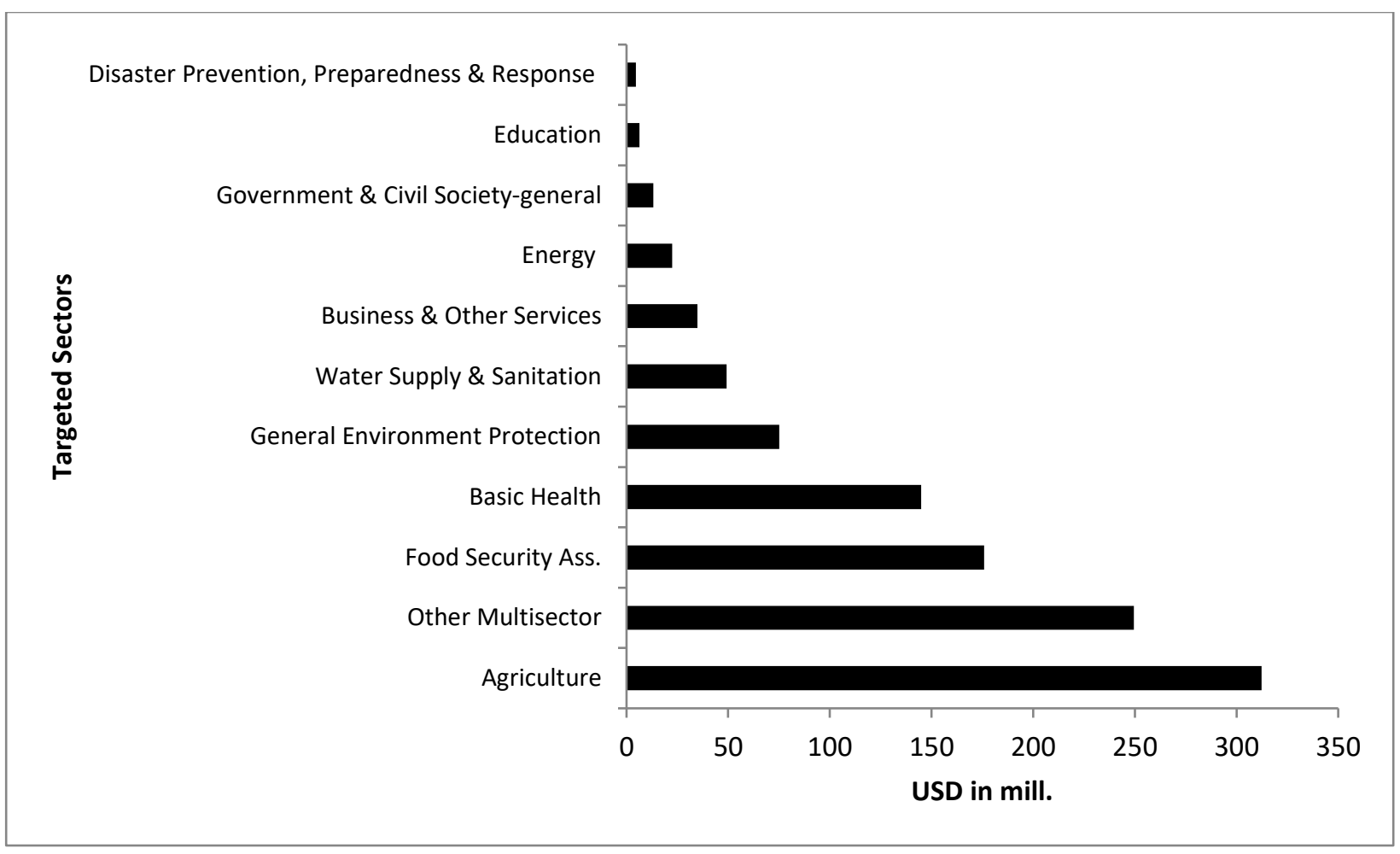

Source: OECD-DAC (2009-2013)

Key economic infrastructure sectors - energy, multi-sector and water receives over $29 \%$ of climaterelated development finance. This is driven mitigation projects in different sectors in general, and by large volume of adaptation projects.

Agriculture accounts for the largest share followed by food security assistance, basic health, general environment protection, water supply and sanitation, energy and education. Mainstreaming of climate change objectives into development co-operation is most evident in the sectors. 


\section{Conclusion and the Way Forward}

In Ethiopia, agriculture is the main stay of the economy. It is the economic sector most sensitive to climate change, including through drought, flooding, soil erosion etc. Despite this situation, Ethiopia has fewer resources, in finance, technology and existing infrastructure, to adapt and cope up with any environmental shocks.

Although climate change poses significant threats, the international response to climate change also offers considerable opportunities for Ethiopia. Climate finance, particularly for adaptation, has been an important issue for Ethiopia sustainable development, given that Ethiopia is already facing the brunt of climate impacts, yet has the least capacity to adapt. There are different bi-lateral and multi-lateral climate finance sources which has both adaptation and mitigation objectives. Financing climate change and development in an integrated manner can maximize climate and development results, targeting both climate and sustainable development goals.

The government of Ethiopia is articulate policy guide and set up institutional framework aimed at addressing the challenges posed by climate change and at capitalizing on the opportunities provided by climate change, like access to climate finance. These responses aim to keep the country's development objectives on track in the context of a changing climate.

The amount of climate finance from the developed countries to Ethiopia shows some fluctuation for the past five years. Climate finance must be disbursed effectively, but sectors like health, education and other infrastructures accessed minimum climate finance. Such inefficiencies also weaken the overall contribution of climate finance to sustainable development. Although the environmental policy and laws set out the basis for dealing with climate change and other environmental problems in Ethiopia, it is essential to recognize that the implications of climate change and the steps required for an effective response go well for sustainable development.

The argument for aligning climate finance and sustainable development is that it results in a more efficient use of financial and human resources than if climate change and development projects are designed and implemented separately. This objective should be pursued —climate finance should, to the extent possible, contribute both to development and to climate change mitigation and/or adaptation. 


\section{The Way Forward}

- Improve domestic resource mobilization.

Strength the capacity of finance institutions as well as environmental agencies to integrate environment into budget decision-making, sector strategies and programs. This allows mobilization of domestic resource.

- Climate change must not be considered as a narrow sectoral issue. Instead a cross-sectoral response is needed.

Sometimes there are some trade-offs in certain cases between development priorities and the actions required to deal with climate change. Therefore, Climate change must not be considered as a narrow sectoral issue. Instead a cross-sectoral response is needed, involving the whole of the government. The response will require cooperation, planning and action across government sectoral ministries and agencies.

- Strong regulatory frameworks required in terms of transparency and accountability.

Strong regulatory frameworks will ensure quality contributions and adherence to social and environmental safeguards and avoid the risk of corruption.

- Encourage demand for and assess the effectiveness of climate financing offered by international public intermediaries to achieve sustainable development along with climate objectives. 


\section{Reference}

Aaron Atteridge, Clarisse Kehler Siebert, Richard J. T. Klein, Carmen Butler and Patricia Tella. 2009. Bilateral Finance Institutions and Climate Change: A Mapping of Climate Portfolios“, Stockholm Environment Institute for the Climate Change.

Adger W.N. 2003. "Adaptation to Climate Change in the Developing World", Progress in Development Studies, Vol. 3, No. 3, pp. 179-95.

Atkinson, G., Dietz, S. and Neumayer, E. 2007. Handbook of Sustainable Development, Edward Elgar, Cheltenham.

Barbara Buchner, Angela Falconer, Morgan Hervé-Mignucci, Chiara Trabacchi and Marcel Brinkman. 2011. "The Landscape of Climate Finance” A CPI Report, Climate Policy Initiative, Venice (Italy).

Barbara Buchner, Angela Falconer, Morgan Hervé-Mignucci, Chiara Trabacchi and Marcel Brinkman. 2012. The Landscape of Climate Finance 2012. Climate Policy Initiative.

Barnett. 2009. Country Programme Evaluation: Ethiopia. Evaluation Report (EV697), Department for International Development, government of UK, London.

Bert Metz. 2002. 'Towards an equitable global climate change regime: Compatibility with Art 2 of the Climate Change Convention and the link with sustainable development' Climate Policy 211, 212.

Beyene, A.D., and S.F. Koch. 2012. "Clean Fuel Saving Technology Adoption in Urban Ethiopia." Energy Economics 36: 605-613.

Bizikova L., Robinson J. and S. Cohen. 2007. Linking Climate Change and Sustainable Development at the Local Level. Climate Policy, Special Issue 7(4): 271-277.

Cancun Agreements. 2010. Report of the Conference of Parties on its sixteenth session, Decision 1/CP.16. Paragraph 95-97. Cancun.

Diana M. Liverman. 2009. 'Conventions of climate change: constructions of danger and the dispossession of the atmosphere'. Journal of Historical Geography 279, 289.

Evans, A. 2012. Resources, Risk and Resilience: Scarcity and climate change in Ethiopia. Centre on International Cooperation, NYU, New York.

FDRE. 2002. Proclamation No. 295/2002. Federal Democratic Republic of Ethiopia, Addis Ababa.

FDRE. 2011. Ethiopia's Climate-Resilient Green Economy: Green Economy Strategy. Federal and Democratic Republic of Ethiopia, Addis Ababa.

Fisher, S. 2013. Low carbon resilient development in the least developed countries. IIED. Issue Paper. IIED, London. 
Homer, Caroline S.E., Hanna, Elizabeth and McMichael, Anthony, J. 2009. "Climate change threatens the achievement of the millennium development goal for maternal health". Midwifery. 25 (3): 606-612.

IISD. 2006. Understanding adaptation to climate change in developing countries.

IPCC. 2007. Climate Change 2007: Impacts, Adaptation and Vulnerability. Contribution of Working Group II to the Fourth Assessment Report of the IPCC. M.L. Parry, Cambridge: Cambridge University Press.

MoFED. 2010. Growth and Transformation Plan 2010/11-2014/15. Volume 1. Federal Democratic Republic of Ethiopia, Addis Ababa.

MoWR and NMA. 2007. Climate Change National Adaptation Programme of Action of Ethiopia. FDRE, Addis Ababa.

NMA. 2007. Final Report on Evaluation Criteria for Identifying High Priority Adaptation Activities prepared by B and M Development Consultants for NMA. Addis Ababa, Ethiopia.

OECD-DAC. 2009. http://www.global-mechanism.org/en/our-services/climate-change-funds

OECD-DAC. 2011. "Handbook on the OECD-DAC Climate Markers", OECD.

Oscar Reyes. 2013. "A Glossary of Climate Finance Terms", Institute for Policy Studies, Washington DC.

Ruchi Anand. 2004. International Environmental Justice: A North-South Dimension.

Schlosberg, D. 2007. Defining Environmental Justice. OUP, Oxford.

Swart R. 2003. "Climate Change and Sustainable Development: Expanding the Options", Climate Policy, Vol. 3, Supplement 1, pp. S19-40.

UNFCCC. 1992. UN Framework Convention on Climate Change, Article 1. Definitions.

UNFCCC. 2011. Decision 5/CP.17. paragraph 1. National adaptation plans.

World Bank 2010. Ethiopia: Economics of Adaptation to Climate Change. The World Bank Group, Washington DC.

World Commission on Environment and Development (WCED). 1987. Our common future: The Brundtland report, Oxford: Oxford University Press.

World Economic Forum. 2014. Climate Adaptation: Seizing the Challenge Geneva, Switzerland, 